\title{
Heterocyclic Amine Carcinogen
}

National Cancer Institute

\section{Source}

National Cancer Institute. Heterocyclic Amine Carcinogen. NCI Thesaurus. Code C45180.

A cyclic compound that has at least one nitrogen incorporated into its structure instead of carbon and contains an amino (-NH2) group. Heterocyclic Amines are formed from cooking meat such as beef, pork, fowl, and fish when amino acids and creatine (found in muscle) react at high temperatures. Because of the high temperatures used, frying, broiling, and barbecuing produce the largest amounts of heterocyclic amines. These compounds that result from cooking meat may increase human cancer risk. (NCI05) 